\title{
Maintaining Dual ABET Accreditation in a Computer Science and Engineering Technology Program
}

\section{Dr. Jared Oluoch, University of Toledo}

Dr. Jared Oluoch is an Associate Professor of Computer Science and Engineering Technology (CSET) at the University of Toledo, $\mathrm{OH}$. He is also the Program Director for the CSET and IT programs, where he is responsible for advising, curriculum development, and ABET accreditation. He received his $\mathrm{PhD}$ in Computer Science and Informatics at Oakland University in 2015 


\title{
Maintaining Dual ABET Accreditation in a Computer Science and Engineering Technology Program
}

\author{
Jared Oluoch, Dan Solarek, Hong Wang \& Weiqing Sun
}

March 16, 2020

\begin{abstract}
The Computer Science and Engineering Technology (CSET) program at The University of Toledo is unique in the sense that it draws both from Computer Engineering Technology and Computer Science and Engineering (CSE) to tailor-make a curriculum that involves both theoretical and hands-on learning. This paper demonstrates how the CSET program, housed in the Department of Engineering Technology at The University of Toledo, satisfies both ABET Computing Accreditation Commission (CAC) and Engineering Technology Accreditation Commission (ETAC) curriculum requirements. Data from Educational Benchmarking Inc. (EBI) demonstrate that the CSET program's performance is at par or almost at par with similar institutions offering Computer Science or Computer Engineering Technology programs nationally. The authors hope that this paper will motivate other programs nationally to adopt the CSET model to produce students that are well-rounded both in theoretical and hands-on learning.
\end{abstract}

\section{Introduction}

In January 1999, The Ohio Board of Regents (OBOR) approved the creation of The Computer Science and Engineering Technology (CSET) program at The University of Toledo. The Technology Accreditation Commission (TAC) of the Accreditation Board for Engineering and Technology (ABET) made an accreditation visit to the CSET program in October 2000. In the general review of 2006, the CSET program was reviewed by both Computing Accreditation Commission (CAC) and TAC of ABET. The CSET program is currently accredited by both CAC and Engineering Technology Accreditation Commission (ETAC) - the successor of TAC. This paper demonstrates how the CSET program, housed in the Department of Engineering Technology at The University of Toledo, satisfies both ABET Computing Accreditation Commission (CAC) and Engineering Technology Accreditation Commission (ETAC) curriculum requirements. 


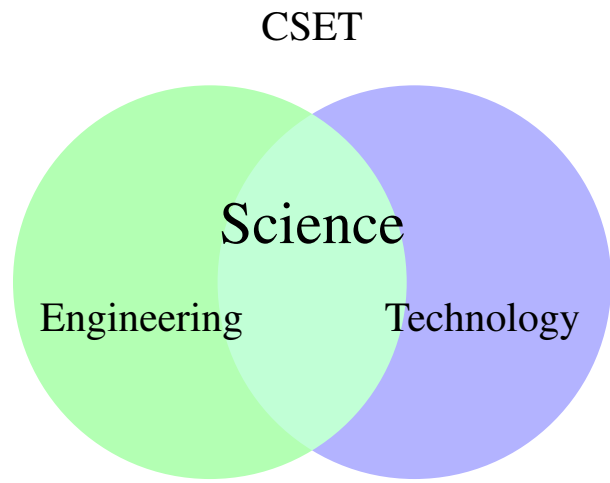

Figure 1. Relationship between CSET and Computer Science and Engineering Program

Figure 1 illustrates the ideal relationship between the Computer Science Engineering (CSE) and CSET programs at The University of Toledo. As can be seen, the two programs have an overlap in terms of the Computer Science content. This overlap is conceptual more than actual as the two programs do not currently share a common list of Computer Science courses. Rather, the Computer Science content for the CSET program is delivered in a series of courses that are tailored to the backgrounds and learning styles of our students. The CSET degree program focuses on two complementary disciplines; Computer Science and Computer Engineering Technology. The Computer Engineering Technology content of the program draws from the tradition of engineering technology programs in that it is primarily applications-oriented with a focus on hands-on education. This content is a major component of the CSET program that satisfies ABET ETAC Criteria. The Computer Science content of the program was enhanced and redesigned after Fall 2006 to meet ABET CAC Criteria.

The CSET program is a mid-station between Computer Science and Computer Engineering Technology. The program is geared primarily to students that enjoy hands-on or Project-Based Learning (PBL). Experiential learning effectively engages students ${ }^{1,2}$, supports technology and collaboration $^{3,4,5,6}$, reduces failure rates ${ }^{7}$, and exposes students to Science, Technology, Engineering and Mathematics (STEM) careers $^{8}$.

// The rest of this paper is structured as follows.

\section{ABET Student Outcome Criteria}

Both ETAC and CAC require accredited programs to follow the student outcome criteria. Students in CAC accredited programs must satisfy outcome criteria by having the ability to:

1. Analyze a complex computing problem and to apply principles of computing and other relevant disciplines to identify solutions;

2. Design, implement, and evaluate a computing-based solution to meet a given set of computing requirements in the context of the program's discipline;

3. Communicate effectively in a variety of professional contexts;

4. Recognize professional responsibilities and make informed judgments in computing practice based on legal and ethical principles; 
5. Function effectively as a member or leader of a team engaged in activities appropriate to the program's discipline.

Students in ETAC accredited programs must have the ability to:

1. Apply knowledge, techniques, skills and modern tools of mathematics, science, engineering, and technology to solve well-defined engineering problems appropriate to the discipline;

2. Design solutions for well-defined technical problems and assist with the engineering design of systems, components, or processes appropriate to the discipline;

3. Apply written, oral, and graphical communication in well-defined technical and non-technical environments; and an ability to identify and use appropriate technical literature;

4. Conduct standard tests, measurements, and experiments and to analyze and interpret the results;

5. Function effectively as a member of a technical team.

Since the CSET program is both accredited by CAC and ETAC, we collect and analyze student outcome data to satisfy both CAC and ETAC criteria. As can be observed from CAC and ETAC criteria above, criteria 1, 2, 3, and 5 for both ETAC and CAC are not too different in their requirements. For criteria 4 for both ETAC and CAC, the CSET program specifically looks for course outcome to satisfy both CAC and ETAC. Not every course is utilized to satisfy all student outcomes. Different courses are mapped with particular student outcomes to ensure all outcomes are measured and satisfied.

Let's take CSET 1200 Object-Oriented Programming \& Data Structures as example to demonstrate how we collect student outcomes for both CAC and ETAC. In this example, let's focus on CAC and ETAC student outcomes 1 and 2. Below is a list of questions that were used in an examination to test and demonstrate achievement of the student outcomes.

1. Write a program that accomplishes the following

Generates a random number

Asks the user to guess the random number generated

If guess is not between 1 and 10, print message "no!"

If user has guessed the number correctly, print out "You got it!"

Otherwise, print the correct random number generated.

2. Write a Java program that asks the user to enter three integers. Use an if else statement to print out the largest integer.

3. Write a for loop that asks the user to enter five integers. After the user enters the five integers, the program calculates and displays the sum of the five integers. 


\section{ABET ETAC Curriculum Criteria}

Beginning 2019-2020 accreditation cycle, ABET ETAC criteria 5 states that baccalaureate Engineering Technology programs satisfy the following requirements.

1. Mathematics: Application of integral and differential calculus, or mathematics above the level of algebra and trigonometry;

2. Physical and natural sciences;

3. A capstone or integrating experience;

4. Cooperative education;

5. An advisory committee with representatives from the program's constituents;

6. Discipline specific content of the curriculum that focus on applied aspects of science and engineering and must:

Represent at least one-third of the total credit hours for the curriculum but no more than two-thirds of the total credit hours for the curriculum;

Include a technical core preparing students for the increasingly complex technical specialties later in the curriculum;

Develop student competency in the discipline;

Include design considerations appropriate to the discipline and degree level such as: industry and engineering standards and codes; public safety and health; and local and global impact of engineering solutions on individuals, organizations and society; and

7. Mathematics: Application of integral and differential calculus, or mathematics above the level of algebra and trigonometry;

8. Physical and natural sciences;

9. A capstone or integrating experience;

10. Cooperative education;

11. An advisory committee with representatives from the program's constituents;

In addition, ABET ETAC requires that Computer Engineering Technology and other similarly named baccalaureate programs must satisfy the following additional program specific criteria.

1. Application of electric circuits, computer programming, associated software applications, analog and digital electronics, microcontrollers, operating systems, local area networks, and engineering standards to the building, testing, operation, and maintenance of computer systems and associated software systems;

2. Application of natural sciences and mathematics at or above the level of algebra and trigonometry to the building, testing, operation, and maintenance of computer systems and associated software systems; 
3. Analysis, design, and implementation of computer system hardware and software;

4. Application of project management techniques to computer systems; and

5. Utilization of statistics/probability, transform methods, discrete mathematics, or applied differential equations in support of computer systems and networks.

\section{ABET CAC Curriculum Criteria}

ABET CAC criteria 5 requires that baccalaureate computing programs satisfy the following requirements.

1. At least 30 semester credit hours or equivalent of up-to-date coverage of fundamental and advanced computing topics that provide depth and breadth in:

Techniques, skills, and tools necessary for computing practice;

Principles and practices for secure computing;

Local and global impacts of computing solutions on individuals, organizations, and society.

2. Mathematics appropriate to the discipline.

In addition, ABET CAC states that Computer Science and other similarly named computing programs must satisfy the following program specific criteria.

1. At least 40 semester credit hours or equivalent of Computer Science that must include:

Substantial coverage of algorithms and complexity, computer science theory, concepts of programming languages, and software development;

Substantial coverage of at least one general-purpose programming language;

Exposure to computer architecture and organization, information management, networking and communication, operating systems, and parallel and distributed computing;

The study of computing-based systems at varying levels of abstraction;

A major project that requires integration and application of knowledge and skills acquired in earlier course work;

2. At least 15 semester credit hours (or equivalent) that must include discrete mathematics and must have mathematical rigor at least equivalent to introductory calculus;

3. At least six semester credit hours (or equivalent) in natural science course work intended for science and engineering majors. 


\section{CSET Curriculum}

The CSET curriculum is designed to meet both CAC and ETAC requirements. The curriculum also meets The University of Toledo core curriculum courses: English composition, Mathematics, Humanities, Social Sciences, Natural Sciences, Electives, and Multicultural studies.

Graduates of the CSET program may go for careers in 1) Software Engineering, 2) Database Systems, 3) Computer Networks, and 4) Web Services. Specific classes that prepare students in the areas aforementioned respectively are CSET 1100, CSET 1200, CSET 3600, and CSET 4250

(for Software Engineering); CSET 3300 (for Database Systems); CSET 2200 and CSET 4750 and CSET 4850 (for Computer Networks); and CSET 3200, CSET 3250, CSET 4100, and CSET 4150 (for Web Services). Students that satisfactorily complete CSET 2200 and CSET 4750 should be able to successfully take Cisco Certified Network Associate (CCNA) exam. Figure 1 shows the CSET Program's flow chart.

\section{Continuous Improvement}

To continuously improve the program, the CSET faculty meet every semester to review student outcomes for all CSET courses for the preceding semester. In the meetings, faculty discuss ways to improve learning outcomes and suggest remedial recourse as needed. The faculty document results of the courses they taught the previous semester in a form designed to capture students' performance and progress. The form captures the following details.

1. Were changes implemented since the last time this course was taught? If yes, what changes were made since the last time this course was taught? Did these changes improve the course?

2. Are changes called for the next time this course is taught? If yes, what changes should be made the next time this course is taught?

3. Did the students demonstrate achievement of the student outcomes specific to this course? Cite evidence from your direct assessment of student outcomes (direct evidence include homework, projects, and examinations).

Faculty are required to present summary data that support achievement or lack thereof of the student learning outcomes usually in a table that lists the CSET student learning outcomes for the course and the assessment instrument used to evaluate achievement of each outcome. Each assessment instrument is a component of the course that is focused on the associated student learning outcome.

Faculty also provide a table for each course that shows a summary of the raw data for the direct evidence that each assessment instrument generates. Let's take CSET 4100 Server-Side Programming as an example. An assessment on the need for continuous improvement could include: a) Questions in two homework assignments involving Java web application and deployment to reveal mastery of CAC and ETAC outcome 4; b) Two programming assignments involving Java server-side scripting designed to reveal mastery of CAC and ETAC outcome 1 . 
Figure 1: University of Toledo CSET Curriculum

\section{Computer Science \& Engineering Technology Curriculum - Full Time (Effective Fall 2013)}

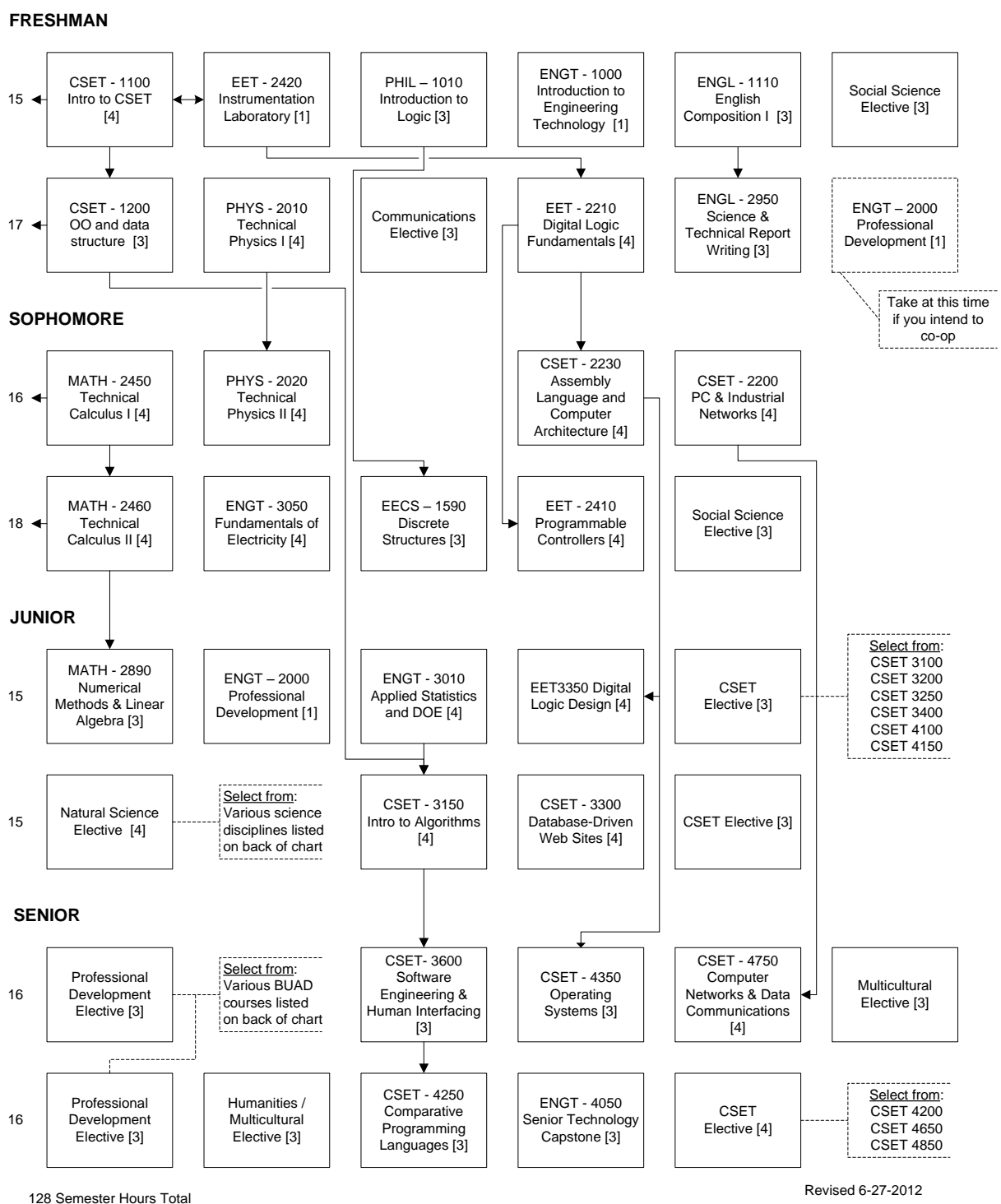


If students did not meet the outcome, faculty recommend ways to improve the outcome in the next semester the course is offered. One such suggestion may include designing a course project and guiding the students over the course of a semester to ensure the student outcomes are met and the loop is closed.

The CSET faculty meet annually with the Industrial Advisory Board (IAB) to review the Program Education Objectives (PEOs) and curriculum. The IAB is composed of members from the local industry in various computing sectors such as software engineering, computer networks, and web services. The IAB suggest to faculty state-of-the art software that need to be integrated in course content, and the skills set that are required of graduates when they enter the job market. Faculty take into account feedback from the IAB to improve course content and course delivery.

\section{Comparison of the CSET Program to Other Similar Benchmark Institutions}

During the final semester of a student's senior year, students are asked to complete a standard survey that is provided to all College of Engineering departments. In this survey, students are asked to rate their experiences with their education on a 1 (low) to 7 ( high) scale. While not asked directly about program outcomes, many groups of questions can be inferred to relate to ABET ETAC student outcomes. Educational Benchmarking Inc. (EBI) compiles and analyzes the surveys and provides data regarding the results. The results are also compared to a select group of six other similar benchmark institutions (Select 6), to a Carnegie class set of institutions and to the entire sample of all participating institutions. These comparisons allow one to determine how the program compares to other institutions on a regional and national scale. For threshold scores when using EBI results to ascertain the achievement of program outcomes, it is deemed that the average of the annual EBI ratings for a category will not significantly trail the peer institutions provided for comparison.

The CSET program performance is at par with other similar programs within the College of Engineering at The University of Toledo, the select 6 schools, and a Carnegie class. The Select six comparison group contains EBI results from the following schools: Texas A\& M - Kingsville, University of Dayton Engineering Technology Department, Prairie View A \& M, Youngstown State, Northeastern University, and Louisiana State University.

Based on this data, it appears that the student opinions in the CSET program are comparable with student opinions within the Engineering Technology department and among peer institutions. This data suggests that our graduates will assume leadership roles in business and industry and make technical contributions to design, development, and manufacturing in their practice of computer science and engineering technology (PEO 1). Our graduates will have a sufficient depth of understanding in computer science, and the skills, confidence, professionalism and experience necessary for successful careers in computer science and related fields (PEO 2). Also, our graduates will engage in professional development or post-graduate education to pursue flexible career paths adapting to future technological changes (PEO 4). Responses to the humanistic elements of the program outcome suggest the program investigate further whether the CSET program is providing students with an understanding of some of the social contexts within which their technical contributions will be applied (PEO 3).

The trend data suggests that student opinions are average or above average with other student 
opinions within the department and among other benchmark institutions but fluctuate somewhat over the years.

Table 1 summarizes the average EBI survey results from 2011 to 2015 . This survey is based on the old ABET ETAC Student outcomes a through $\mathrm{k}$. The old ETAC student outcome criteria on which the EBI data was analyzed are the following.

Table 1: Average EBI Survey Results 2010-2015

\begin{tabular}{cccccc}
\hline \hline Outcomes & CSET & UT ET & Select 6 & Carnegie & All \\
\hline $\mathrm{a}$ & 5.45 & 5.48 & 5.72 & 5.64 & 5.57 \\
$\mathrm{~b}$ & 5.54 & 5.70 & 5.95 & 5.82 & 5.84 \\
$\mathrm{c}$ & 5.36 & 5.56 & 5.75 & 5.71 & 5.66 \\
$\mathrm{~d}$ & 4.97 & 5.14 & 5.31 & 5.31 & 5.16 \\
$\mathrm{e}$ & 5.46 & 5.49 & 5.67 & 5.64 & 5.61 \\
$\mathrm{f}$ & 5.48 & 5.62 & 5.86 & 5.82 & 5.76 \\
$\mathrm{~g}$ & 5.48 & 5.60 & 5.73 & 5.74 & 5.66 \\
$\mathrm{~h}$ & 5.66 & 5.65 & 5.86 & 5.80 & 5.74 \\
$\mathrm{i}$ & 5.76 & 5.89 & 5.80 & 5.92 & 5.78 \\
$\mathrm{j}$ & 5.30 & 5.44 & 5.46 & 5.45 & 5.42 \\
$\mathrm{k}$ & 6.01 & 5.64 & 6.28 & 6.37 & 6.22 \\
\hline
\end{tabular}

A An ability to select and apply the knowledge, techniques, skills, and modern tools of the discipline to broadly-defined engineering technology activities,

B An ability to select and apply a knowledge of mathematics, science, engineering, and technology to engineering technology problems that require the application of principles and applied procedures or methodologies,

C An ability to conduct standard tests and measurements; to conduct, analyze, and interpret experiments; and to apply experimental results to improve processes,

D An ability to design systems, components, or processes for broadly-defined engineering technology problems appropriate to program educational objectives,

E An ability to function effectively as part of a team,

F An ability to identify, analyze, and solve broadly-defined engineering technology problems,

G An ability to apply written, oral, and graphical communication in both technical and non-technical environments; and an ability to identify and use appropriate technical literature,

$\mathrm{H}$ An understanding of the need for and an ability to engage in self-directed continuing professional development,

I An understanding of and a commitment to address professional and ethical responsibilities including a respect for diversity, 
J An understanding of and a commitment to address professional and ethical responsibilities including a respect for diversity,

$\mathrm{K}$ A commitment to quality, timeliness and continuous improvement.

\section{Conclusion}

This paper presented the curriculum for the CSET program. It demonstrated how the program is uniquely designed to meet ABET CAC and ETAC curriculum requirements. Further, it described the program's continuous improvement process that involves the program's constituents. It is hoped that the CSET model may be replicated across the nation in Computer Science and Computer Engineering Technology programs. Data from Educational Benchmarking Inc. (EBI) demonstrate that the CSET program's performance is at par or almost at par with similar institutions offering Computer Science or Computer Engineering Technology programs nationally. The authors hope that this paper will motivate other programs nationally to adopt the CSET model to produce students that are well-rounded both in theoretical and hands-on learning.

\section{References}

[1] Martin Haberman. Selecting'star'teachers for children and youth in urban poverty. Phi Delta Kappan, 76(10): $777,1995$.

[2] Clayton M Christensen, Michael B Horn, and Curtis W Johnson. How'disruptive innovation'will change the way we learn. Education Week, 27(39):25-36, 2008.

[3] Robert Tinker. Thinking about science. CEEB, 57pp, 1992.

[4] Richard Ruopp, Shahaf Gal, Brian Drayton, and Meghan Pfister. LabNet: Toward a community of practice. Routledge, 2012.

[5] Joseph Krajcik, Phyllis Blumenfeld, Ron Marx, and Elliot Soloway. Instructional, curricular, and technological supports for inquiry in science classrooms. 1998.

[6] J Krajcik and CM Czerniak. Teaching science to children: A project-based science approach, 2007.

[7] Scott Freeman, Sarah L Eddy, Miles McDonough, Michelle K Smith, Nnadozie Okoroafor, Hannah Jordt, and Mary Pat Wenderoth. Active learning increases student performance in science, engineering, and mathematics. Proceedings of the National Academy of Sciences, 111(23):8410-8415, 2014.

[8] Alok K Verma, Daniel Dickerson, and Sue McKinney. Engaging students in stem careers with project-based learning_-marinetech project. Technology and Engineering Teacher, 71(1), 2011. 